\title{
O ATENDIMENTO EDUCACIONAL ESPECIALIZADO NA PRÁTICA PEDAGÓGICA DE UMA PROFESSORA EM UMA ESCOLA DO MUNICÍPIO DE PASSO DE TORRES/SC
}

\author{
THE SPECIALIZED EDCUCATIONAL SERVICE IN THE PEDAGOGICAL \\ PRACTICE OF A TEACHER IN A MUNICIPAL SCHOOL OF PASSO DE \\ TORRES/SC
}

\author{
Jucélia Maciel do Amaral ${ }^{1}$ \\ Zélia Medeiros Silveira ${ }^{2}$
}

\begin{abstract}
RESUMO: Esta pesquisa tem como objetivo analisar a prática pedagógica de uma professora da Sala de Recursos Multifuncionais integrante ao Atendimento Educacional Especializado em uma Escola Municipal de Passo de Torres/SC, discutindo sua articulação com o ensino regular. Para tanto foi realizado um estudo teórico acerca da prática pedagógica da professora, bem como uma pesquisa de campo de natureza básica e de cunho qualitativo, utilizando-se como instrumento de coleta de dados a entrevista narrativa. A entrevista revelou que a professora implantou na escola em estudo, a Sala de Recursos Multifuncionais, espaço do AEE. Nesta sala foram atendidos educandos com deficiências, transtornos ou distúrbios. Sobre a prática pedagógica da professora, percebeu-se que a mesma se dedica de forma intensiva aos atendimentos dos seus educandos, propondo atividades diferenciadas, considerando as suas características de aprendizagem. A articulação do serviço do AEE com o ensino regular ocorre por meio de encontros para discussão do processo de aprendizagem, realinhamento de estratégias de ensino e procedimentos de avaliação.
\end{abstract}

PALAVRAS CHAVE: Atendimento Educacional Especializado (AEE). Educação Especial. Professor.

ABSTRACT: This research has as a goal to analyse the pedagogical practice of a teacher of Multifunctional Resources Room integrated to Specialized Educational Service in a municipal school of Passo de Torres/SC, discussing its articulation with the regular education. For that, a theoretical study around the pedagogical practice of the teacher was performed, as well as a field research of a basic nature and of a qualitative nature, using as instrument of data collection the narrative interview. The interview revealed that the teacher implanted in the school under study the Multifunctional Resources Room, space of SES (Specialized Educational Service). In

\footnotetext{
${ }^{1}$ Graduada em Pedagogia da Unesc - juceliaamaral@ live.com

${ }^{2}$ Graduada em Pedagogia, Supervisão Escolar, Psicologia Escolar, Psicopedagogia Institucional e Clinica. Mestre em educação. Pesquisadora dos grupos GPCA (grupo de pesquisa em ciências e educação ambiental) e Sustentabilidade e saúde ambiental - zms@unesc.net

Saberes Pedagógicos, Criciúma, v. 5, nº1, janeiro/abril 2021. - Curso de Pedagogia - UNESC
} 


\section{SABERES PEDAGÓGICOS}

Revista do Curso de Graduaçào de Pedagogia - Unesc

ISSN 2526-4559

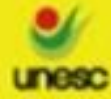

Geles senente

this room were attended students with disabilities, disorders or disturbs. About the pedagogical practice of the teacher, it was noticed that she dedicated herself intensively to the attendance of her students, proposing different activities considering their learning characteristics. The articulation of the SES service with regular education occurs through meetings to discuss the learning process, realignment of teaching strategies and evaluation procedures.

KEY WORDS: Specialized Educational Service (SES). Special Education. Teacher.

\section{INTRODUÇÃO}

O Atendimento Educacional Especializado, doravante AEE, é um serviço oferecido pela escola para inclusão de educandos com deficiência, transtornos globais de desenvolvimento e altas habilidades/superdotação, assegurado pela Lei de Diretrizes e Bases da Educação Nacional, disposto no artigo 58 (9394/96). Esse serviço garante aos estudantes a aprendizagem necessária para que possam ultrapassar as barreiras impostas pela deficiência.

$\mathrm{O}$ atendimento ao educando com deficiência deve ocorrer em escolas públicas ou em instituições comunitárias, confessionais ou filantrópicas sem fins lucrativos, conforme estabelece a LDB 9.394/96 em seu artigo 59. Esse atendimento deve ser desenvolvido por professores especializados, no turno inverso ao do ensino regular, em uma sala equipada com recursos de aprendizagem, denominada de Sala de Recursos Multifuncionais.

Por essas razões, o professor responsável pelo AEE na Sala de Recursos deve ser pró-ativo, paciente, pesquisador, devendo criar e recriar, junto com a comunidade escolar, propostas diferenciadas para que o processo de ensino-aprendizagem atenda às necessidades específicas dos estudantes. Desse modo, salienta-se a importância do trabalho do professor da Sala de Recursos como o intermediador da aprendizagem, responsável pela organização de propostas pedagógicas e materiais didáticos adaptados para atender as necessidades do educando.

De acordo com o exposto no Documento Orientador do Programa de Implantação de Salas de Recursos Multifuncionais organizado pelo MEC, SECADI e DPEE ${ }^{3}$ (BRASIL, 2012), essa sala tem como objetivo "apoiar os sistemas públicos de ensino na organização e

\footnotetext{
${ }^{3}$ MEC: Ministério da Educação; SECADI: Secretaria de Educação Continuada, Alfabetização, Diversidade e Inclusão; DPEE: Diretoria de Políticas de Educação Especial.

Saberes Pedagógicos, Criciúma, v. 5, nº1, janeiro/abril 2021. - Curso de Pedagogia - UNESC
} 


\section{SABERES PEDAGÓGICOS}

Revista do Curso de Graduaçào de Pedagogia - Unesc

ISSN 2526-4559

oferta do atendimento educacional especializado e contribuir para o fortalecimento do processo de inclusão educacional nas classes comuns de ensino". Por isso, deve ser "um espaço organizado com equipamentos de informática, ajudas técnicas, materiais pedagógicos e mobiliários adaptados, para atendimento às necessidades educacionais especiais dos alunos.” (BRASIL, 2012, p. 31).

Diante da relevância do tema em estudo, levantou-se a seguinte problemática: como se dá a prática pedagógica de uma professora da Sala de Recursos Multifuncionais integrante ao Atendimento Educacional Especializado em uma Escola Municipal de Passo de Torres/SC.

O desejo de pesquisar esse tema ocorreu quando a pesquisadora atuou no estágionão-obrigatório como estagiária de uma educanda diagnosticada, segundo laudo médico, com: dislexia, discalculia e Transtorno de Déficit de Atenção com Hiperatividade - TDAH. Após algum tempo, a estagiária verificou que a estudante frequentava duas vezes por semana a Sala de Recursos Multifuncionais, na qual recebia AEE. Foi, então, que surgiu o anseio por conhecer mais sobre o atendimento realizado nessa sala, ou seja, a forma como eram trabalhados os conteúdos, as atividades propostas, os projetos pedagógicos, dentre outras questões.

A fim de compreender como esses elementos então interligados ao ensino regular e ao processo de aprendizagem, buscou-se observar, no período de um ano, o desenvolvimento da educanda, tanto na sala de ensino regular, como com a professora da Sala de Recursos. Importante colocar que a estudante em questão estava com dezesseis anos de idade na época e cursava o $9^{\circ}$ ano; tinha um histórico de muitas reprovações e aquele era o último ano naquela escola, uma vez que só ofertava o Ensino Fundamental. Isso posto, a estagiária teve a oportunidade de participar de um conselho de classe, no qual observou-se que os professores do $9^{\circ}$ ano esperavam pelo fim do ano letivo para "passar de nível/ano" a educanda, e se "livrarem da elaboração de aulas adaptadas", "provas diferenciadas" e de todo o acompanhamento que se fazia necessário a ela. ${ }^{4}$

No entanto essa pesquisa não foi realizada nesta escola, mas, foi pensando nessas questões que se optou pela investigação proposta neste trabalho, ou seja, a análise de como é desenvolvida a prática pedagógica de uma professora da Sala de Recursos Multifuncionais integrante do AEE, discutindo sua articulação com o ensino regular. Vale ressaltar que a

\footnotetext{
${ }^{4}$ Falas utilizadas rotineiramente pelos professores da educanda em questão.

Saberes Pedagógicos, Criciúma, v. 5, nº 1, janeiro/abril 2021. - Curso de Pedagogia - UNESC
} 


\section{SABERES PEDAGÓGICOS}

Revista do Curso de Graduaçào de Pedagogia - Unesc

ISSN 2526-4559

integração de educandos com deficiência nas escolas de ensino regular já acontece, mas, muitas vezes, não cumpre o papel esperado pelas famílias e conforme é assegurado pelas políticas da educação inclusiva. É importante lembrar que o AEE faz parte da Proposta da Educação Inclusiva assegurada pela Política Nacional de Educação Especial na Perspectiva da Educação Inclusiva (2008), o qual é ofertado em algumas escolas e/ou centros de AEE, tendo papel fundamental na aprendizagem e no desenvolvimento dos educandos.

Somado a isso, elencaram-se os seguintes objetivos específicos: a) constatar os motivos geradores da implantação da Sala de Recursos Multifuncionais na escola pesquisada; b) examinar o papel do professor responsável pelo AEE no processo de ensino-aprendizagem; c) diferenciar as formas de atendimentos realizados no AEE; d) identificar o público-alvo e suas necessidades pedagógicas; e) verificar quais procedimentos são necessários para a realização dos atendimentos; e f) compreender o papel do AEE a partir das bibliografias estudadas.

Desse modo, para dar conta dos propósitos deste trabalho, decidiu-se realizar, além do estudo teórico, um estudo de caso, acerca da prática pedagógica de uma professora da Sala de Recursos Multifuncionais. Assim, esta pesquisa é de natureza básica, de cunho qualitativodescritivo, que utiliza, como instrumento de coleta de dados, a entrevista narrativa com uma professora da Sala de Recursos Multifuncionais e a observação da sua prática, além da análise do plano de aula, das atividades elaboradas para os atendimentos e de alguns aspectos do Projeto Político Pedagógico da escola.

\section{O ATENDIMENTO EDUCACIONAL ESPECIALIZADO E SUA REGULAMENTAÇÃO}

O AEE utiliza como espaço de trabalho a Sala de Recursos Multifuncionais da própria escola ou em outra instituição de ensino regular, no turno inverso, não substituindo as classes regulares. É sobretudo, na rede pública de ensino que comumente é encontrado. Segundo a Lei de Diretrizes e Bases da Educação Nacional 9394 (BRASIL, 1996), doravante LDB, esse serviço presta atendimento às crianças que apresentam deficiência, transtornos globais de desenvolvimento e/ou altas habilidades/superdotação. 
A LDB 9.394/96 no seu artigo 59, afirma, ainda, que os sistemas de ensino deverão garantir a esses educandos do AEE:

\begin{abstract}
I - currículos, métodos, técnicas, recursos educativos e organização específicos, para atender às suas necessidades; II - terminalidade específica para aqueles que não puderem atingir o nível exigido para a conclusão do ensino fundamental, em virtude de suas deficiências, e aceleração para concluir em menor tempo o programa escolar para os superdotados; [...] IV - educação especial para o trabalho, visando a sua efetiva integração na vida em sociedade, inclusive condições adequadas para os que não revelarem capacidade de inserção no trabalho competitivo, mediante articulação com os órgãos oficiais afins, bem como para aqueles que apresentam uma habilidade superior nas áreas artística, intelectual ou psicomotora. (BRASIL, 1996, p. 25).
\end{abstract}

Discutir o papel e a importância do AEE, portanto, é falar sobre inclusão. A respeito disso, a Constituição Federal do Brasil de 1988 enfatiza, nos artigos 205 e 206, o dever do Estado de garantir a permanência na escola de todos os educandos entre os quatro e dezessete anos. Essa garantia se refere ao acesso à educação básica, contemplando de maneira plena o desenvolvimento dos educandos.

A Política Nacional de Educação Especial na Perspectiva da Educação Inclusiva (BRASIL, 2008) apresenta, como objetivo geral, o compromisso da União na prestação de apoio técnico e financeiro aos sistemas públicos de ensino dos Estados, do Distrito Federal e dos Municípios, sendo, então, de responsabilidade da União, a manutenção do AEE.

Sobre o AEE, as Diretrizes Curriculares Nacionais Gerais da Educação descrevem que "considera-se um Atendimento Educacional Especializado o conjunto de atividades, recursos de acessibilidade e pedagógicos organizados institucionalmente, prestando de forma complementar ou suplementar à formação dos educandos no ensino regular.” (BRASIL, 2013, p.280). Nesse mesmo documento, nota-se que a definição da oferta do AEE deve ocorrer em todas as etapas, níveis e modalidades de ensino, sendo parte integrante do processo educacional.

Acerca do público-alvo do AEE, as DCNs (2013) definem:

I- Educandos com deficiência: aqueles que têm impedimentos de longo prazo de natureza física, intelectual, mental ou sensorial. II- Educandos com transtornos globais do desenvolvimento: aqueles que apresentam um quadro de alterações no desenvolvimento neuropsicomotor, comprometimento nas relações sociais, na comunicação ou estereotipias motoras. [...] . II- Educandos com altas habilidades/superdotação: aqueles que apresentam um potencial elevado e grande envolvimento com as áreas do conhecimento humano, isoladas ou combinadas: intelectual, liderança, psicomotora, artes e criatividade. (BRASIL, 2013, p. 282).

Saberes Pedagógicos, Criciúma, v. 5, nº1, janeiro/abril 2021. - Curso de Pedagogia - UNESC 


\section{SABERES PEDAGÓGICOS}

Revista do Curso de Graduaçào de Pedagogia - Unesc

ISSN 2526-4559

Percebem-se, no que diz respeito ao perfil dos educandos com deficiência, transtornos globais de desenvolvimento e/ou altas habilidades/superdotação, as singularidades de cada um, devendo o professor do AEE realizar atendimentos específicos e diferenciados a cada frequentador, promovendo avanços no seu processo de aprendizagem. Além disso, tendo em vista as especificidades do público do AEE, aponta-se a necessidade de formação continuada aos segundos professores que atendem o aluno com deficiência na sala de aula, assim como também aos do ensino regular, para que possam atuar de forma integrada e colaborativa.

A Sala de Recursos Multifuncionais é parte integrante do AEE, constituindo-se como um ambiente de ensino e aprendizagem no qual o educando desenvolve habilidades significativas para se tornar protagonista do seu aprendizado, desenvolvendo-se progressivamente. Assim sendo, a implantação da Sala de Recursos Multifuncionais é mencionada em diversos documentos legais.

As Diretrizes Curriculares Nacionais para Educação Básica (2013, p. 283) expressam, no capítulo designado "Diretrizes Operacionais para o atendimento educacional especializado na Educação Básica, modalidade Educação Especial”, que “O projeto pedagógico da escola de ensino regular deve institucionalizar a oferta do AEE prevendo na sua organização: sala de recursos multifuncionais: espaço físico, mobiliário, materiais didáticos, recursos pedagógicos e de acessibilidade e equipamentos específicos.” (BRASIL, 2013).

Nota-se a importância da ambientação da sala, no sentido de que seja equipada com todos os recursos citados anteriormente, o que poderá promover avanços no desenvolvimento dos educandos que a frequentam. Nesse sentido, sobre o ensino regular, as DCNs definem como recursos de acessibilidade necessárias à inclusão dos alunos:

[...] aqueles que asseguram condições de acesso ao currículo dos alunos com deficiência ou mobilidade reduzida, promovendo a utilização dos materiais didáticos e pedagógicos, dos espaços, dos mobiliários e equipamentos, dos sistemas de comunicação e informação, dos transportes e dos demais serviços. (BRASIL, 2013, p. 164).

Com isso, percebe-se a amplitude e a significância dos recursos que devem ser utilizados e reconhecidos no dia-a-dia dos educandos com deficiência, transtornos globais de 
desenvolvimento e/ou altas habilidades/superdotação, os quais devem ser parte não somente dos atendimentos, mas em todo o meio no qual estão inseridos. Dentro dessa ótica, segundo Fiegenbaum (2009), além dos recursos que colaboram para um melhor desenvolvimento da aprendizagem dos educandos do AEE, faz-se necessário um professor comprometido com o desenvolvimento e a aprendizagem dos alunos, cujo aprofundamento teórico sobre as deficiências, distúrbios e dificuldades de aprendizagem sejam parte de sua rotina.

Dessa maneira, também é essencial a utilização das tecnologias dispostas nas Salas de Recursos Multifuncionais, para que as especificidades dos educandos possam ser atendidas e potencializada na sua aprendizagem. Nesse sentido, cabe às Secretarias dos Estados, junto com o Ministério da Educação:

[...] realizar a distribuição de equipamentos, mobiliários e materiais pedagógicos e de acessibilidade para a organização das salas de recursos multifuncionais destinadas ao atendimento educacional especializado. Os municípios e estados indicam escolas que possuam matrículas de alunos com deficiência, transtornos globais de desenvolvimento e altas habilidades/superdotação. (BRASIL, 2009).

Contudo, para implantar uma Sala de Recursos Multifuncionais, é necessária uma demanda significativa de procura por matrículas no AEE, com base na qual, conforme Brasil (2009), e o Conselho estadual de educação de Santa Catarina, com a sua Resolução nº 100 (BRASIL, 2016) a Secretaria de Educação de cada Município deve encaminhar para uma escola pública da região onde mora o educando, todos aqueles que apresentam deficiência, transtornos globais de desenvolvimento e/ou altas habilidades/superdotação, para que ali seja implantada uma Sala. As razões dessa concentração de alunos em uma escola se justifica pelas poucas condições financeiras dos órgãos competentes em implantar uma sala em cada escola que obtiver uma pequena procura pelo serviço do AEE.

Fica designada à Secretaria de Educação de cada Estado ou Município a responsabilidade sobre a Sala de Recursos Multifuncionais, de acordo com o articulado no documento organizado pelo Ministério da Educação, intitulado: Programa de Implantação de Sala de Recursos Multifuncionais (2010). Salienta-se, no mesmo documento, a subdivisão da sala de recursos em Sala Tipo I e Sala Tipo II.

A Sala Tipo I deve conter:

Saberes Pedagógicos, Criciúma, v. 5, nº1, janeiro/abril 2021. - Curso de Pedagogia - UNESC 
Equipamentos Materiais Didático/Pedagógico, 02 Microcomputadores, 01 Material Dourado, 01 Laptop, 01 Esquema Corporal, 01 Estabilizador, 01 Bandinha Rítmica, 01 Scanner, 01 Memória de Numerais, 01 Impressora laser, 01 Tapete Alfabético Encaixado, 01 Teclado com colméia, 01Software Comunicação Alternativa, 01 Acionador de pressão, 01 Sacolão Criativo Monta Tudo, 01 Mouse com entrada para acionador, 01 Quebra Cabeças - seqüência lógica, 01 Lupa eletrônica, 01 Dominó de Associação de Ideias Mobiliários, 01 Dominó de Frases, 01 Mesa redonda, 01 Dominó de Animais em Libras, 04 Cadeiras, 01 Dominó de Frutas em Libras, 01 Mesa para impressora, 01 Dominó tátil, 01 Armário, 01 Alfabeto Braille, 01 Quadro branco, 01 Kit de lupas manuais, 02 Mesas para computador, 01 Plano inclinado - suporte para leitura, 02 Cadeiras, 01 Memória Tátil. (BRASIL, 2010).

Já, a Sala Tipo II, atende os educandos com deficiência visual e deve dispor dos equipamentos e materiais didático/pedagógicos referenciados, acrescendo-se "01 Impressora Braille - pequeno porte, 01 Máquina de datilografia Braille, 01 Reglete de Mesa, 01 Punção, 01 Soroban, 01 Guia de Assinatura, 01 Kit de Desenho Geométrico, 01 Calculadora Sonora." (BRASIL, 2010). O funcionamento adequado da Sala de Recursos Multifuncionais é de responsabilidade do MEC e da Secretaria de Educação de cada Estado ou Município. Esses órgãos devem trabalhar junto ao professor responsável, visando ao melhor atendimento aos educandos.

\section{A PROPOSTA PEDAGógica do ATENDIMENTO EDUCACIONAL ESPECIALIZADO}

A proposta pedagógica da escola deve sempre ser articulada com a proposta do AEE, conforme expresso nas DCNs (BRASIL, 2013, p. 280): "O atendimento educacional especializado deve integrar a proposta pedagógica da escola, envolver a participação da família e ser realizado em articulação com as demais políticas públicas.” Segundo as DCNs (BRASIL, 2013), na proposta pedagógica devem constar as condições de acessibilidade de cada aluno, como a permanência na escola e a continuidade nos estudos, a garantia do direito a serem matriculados no ensino regular e no AEE na rede pública ou em instituições comunitárias, confessionais ou filantrópicas sem fins lucrativos.

Ainda, sobre a Proposta do AEE, a Lei Brasileira de Inclusão (2015) diz que se deve construir um:

Saberes Pedagógicos, Criciúma, v. 5, nº1, janeiro/abril 2021. - Curso de Pedagogia - UNESC 


\section{SABERES PEDAGÓGICOS}

Revista do Curso de Graduaçào de Pedagogia - Unesc

ISSN 2526-4559

Projeto pedagógico que institucionalize o atendimento educacional especializado, assim como os demais serviços e adaptações razoáveis, para atender às características dos estudantes com deficiência e garantir o seu pleno acesso ao currículo em condições de igualdade, promovendo a conquista e o exercício de sua autonomia. (BRASIL, 2015, p. 34).

Nesse sentido, o planejamento do projeto pedagógico deve considerar as especificidades de cada educando, corroborando com o desenvolvimento e a aprendizagem de todos. Convém ressaltar outro documento relativo à educação inclusiva, designado Cartilha do AEE, organizada pelo MEC, SEESP, SEED ${ }^{5}$ (BRASIL, 2007), a qual orienta a elaboração e a execução do plano do AEE, auxiliando também os professores que atuam na sala de recursos multifuncionais ou em centros de AEE. Esses centros e salas devem conter espaço físico, mobiliário, materiais didáticos, recursos pedagógicos de acessibilidade e equipamentos específicos para contemplar as especificidades de todos os educandos que a frequentam.

O Plano de Ensino do professor deve ser formulado a partir das necessidades de cada estudante, identificando as diversas atividades a serem desenvolvidas e os recursos a serem utilizados nesse atendimento. Para compreender as diferentes situações que são instituídas nas escolas ou nos centros de AEE, destaca-se a promoção de experiências significativas a partir de atividades pedagógicas diferenciadas, utilizando-se do lúdico e do concreto.

No que se refere às especificidades da prática pedagógica, a Cartilha do AEE (BRASIL, 2007) orienta que a adaptação do conteúdo escolar deve ser realizada pelo próprio membro participante do processo de ensino e aprendizagem, neste caso, o educando. Essa adaptação parte somente dele, da sua emancipação intelectual, que deve ser compreendida na sua essência pelo professor de sala e pelo professor especializado em Educação Especial e no AEE. Deve-se levar em conta que o professor ensina de maneira coletiva, e o aprendente interage individualmente, de forma singular ao objeto de estudo. Portanto, o ensino deve ser diversificado, explorando de várias maneiras a compreensão dos educandos.

Como já mencionado anteriormente, o AEE tem também como objetivo alcançar/ultrapassar as barreiras impostas pela deficiência e pelos transtornos globais de desenvolvimento e/ou altas habilidades/superdotação de cada educando. Por essas razões, a

\footnotetext{
${ }^{5}$ SEESP: Secretaria do Estado de São Paulo; SEED: Secretaria de Estado da Educação de Santa Catarina.

Saberes Pedagógicos, Criciúma, v. 5, nº1, janeiro/abril 2021. - Curso de Pedagogia - UNESC
} 


\section{SABERES PEDAGÓGICOS}

Revista do Curso de Graduaçào de Pedagogia - Unesc

ISSN 2526-4559

inclusão não está vinculada apenas à sua socialização, mas, sobretudo, à sua aprendizagem e ao seu desenvolvimento, a partir de propostas pedagógicas significativas.

Sobre isso, a Política Nacional de Educação Especial na Perspectiva da Educação Inclusiva (BRASIL, 2008) diz que "A educação especial passa a constituir a proposta pedagógica da escola". Desse modo, deve haver integração entre a proposta pedagógica do ensino regular e a proposta do AEE.

No que diz respeito ao desenvolvimento dos educandos, considera-se, segundo a Cartilha do AEE (BRASIL, 2008), que existem diversas transformações dos sujeitos a partir do local em que estão inseridos, do qual fazem parte. Nessa perspectiva, leva-se em conta as modificações do meio e tudo que ele pode provocar. Dessa forma, a instituição deve dispor de serviço pedagógico, demonstrando os ambientes heterogêneos da instituição.

Sendo assim, os atendimentos devem ser avaliados a cada encontro realizado, levando em conta toda e qualquer mudança de comportamento dos educandos. Como diz Milanesi (2011), é preciso compreender o ato de implementação de estratégias de flexibilização, da implementação de procedimentos didáticos pedagógicos e de práticas alternativas, bem como promover a inclusão dos alunos com deficiências, transtornos globais de desenvolvimento e/ou altas habilidades/superdotação.

Assim sendo, o AEE não substitui a escolarização, pois suas atividades são diferentes das realizadas em sala de aula no ensino regular (BRASIL, 2008). Além disso, é importante frisar que o AEE não serve como reforço escolar, mas como complementação ou suplementação dos estudos, visando a promover a aprendizagem e a desenvolver autonomia do educando.

\section{O PAPEL DO PROFESSOR NO ATENDIMENTO EDUCACIONAL ESPECIALIZADO}

O professor responsável pelos atendimentos aos educandos no AEE tem como atribuição elaborar propostas pedagógicas para o melhor desenvolvimento do aluno e, se for necessário, encaminhá-lo para o acompanhamento de fonoaudiólogo, de psicólogo, de fisioterapeutas, entre outros profissionais da área da saúde, bem como realizar visitas às suas

Saberes Pedagógicos, Criciúma, v. 5, nº1, janeiro/abril 2021. - Curso de Pedagogia - UNESC 


\section{SABERES PEDAGÓGICOS}

Revista do Curso de Graduaçào de Pedagogia - Unesc

ISSN 2526-4559

casas, para conhecimento do ambiente familiar. (DORNELES, 2013). De acordo com a Resolução no 436/2012 do MEC, no seu artigo $9^{\circ}$, o professor de AEE tem como função identificar, elaborar, produzir e organizar serviços, recursos pedagógicos e de acessibilidade para que atenuem as barreiras à plena participação dos educandos, considerando suas necessidades específicas. (BRASIL, 2012).

Diante dessas questões, surgem dúvidas em relação à função do professor do AEE. Dorneles (2013), por sua vez, afirma que existem funções que não dizem respeito ao professor do AEE, na prática, mas lhe foram atribuídas, como "dar conta" de educandos considerados problemas, com vulnerabilidade social, comportamental, conflitos com a lei e uso de drogas, mal-entendidos entre os educandos e seus professores, na instituição ou com os colegas.

Outra dificuldade refere-se à identificação do professor responsável do AEE que atua numa sala "bem equipada", "exclusiva", que atende educandos de forma individual, dispondo de uma pasta com todos os dados deles: laudos, acompanhamento médico, relatório da última escola, entre outras informações. Possui, também, horários para cada atendimento, e, quando algum aluno não comparece à aula, ocupa seu tempo com organização de atividades como, por exemplo, criar planos específicos para cada caso atendido. Mas, enfim, nem sempre a realidade condiz com o que se espera dela. Há, ainda, outra questão: como se deve designar o profissional de AEE? É designado como educador especial? Professor da educação especial? Professor especializado? A resposta mais adequada, de acordo com Dorneles (2013), é professor de educação especial ou educador especializado.

Além disso, segundo Dorneles (2013), piadas de muito mal gosto são lançadas a todo momento ao professor do AEE, como: "O lugar destes educandos é na Associação de Pais e Amigos dos Excepcionais (APAE)", "Eles não aprendem mais nada, só atrapalham", "O atendimento tem que ser para os professores". Problematizando essas falas, percebemos o quão necessário é o trabalho com os professores da escola, por meio de formação continuada, para que ocorra entendimento da função da Sala de Recursos Multifuncionais, espaço do AEE.

É importante salientar que, com base nas DCNs (BRASIL, 2013), o professor do AEE possui muitas funções. Dentre elas, pode-se destacar: a) elaborar e colocar em prática o plano do AEE; b) estar disposto a avaliar a funcionalidade e a aplicabilidade de todos os recursos pedagógicos e de acessibilidade; c) otimizar os atendimentos na Sala de Recursos

Saberes Pedagógicos, Criciúma, v. 5, nº 1 , janeiro/abril 2021. - Curso de Pedagogia - UNESC 
Multifuncionais; d) estar disponível para acompanhar o uso dos recursos pedagógicos na sala de aula comum do ensino regular, da mesma maneira em outros ambientes da escola; e e) orientar professores e famílias sobre os recursos pedagógicos e de acessibilidade utilizados pelo aluno, assim como estabelecer articulação com os professores do ensino regular, observando a disponibilização dos serviços, dos recursos pedagógicos, de acessibilidade e das estratégias que promovem a participação dos alunos nas atividades escolares.

Tais pressupostos consideram o professor como sujeito fundamental no processo de ensino e aprendizagem dos educandos frequentadores do AEE, sendo essencial todo acompanhamento prestado por ele. Lembra-se também que, segundo Fiegenbaum (2009), alunos que demonstram alguma situação de desvantagem são excluídos da classe, o que exige que o professor intervenha, buscando, por meio de sua formação e conhecimento, estratégias para contornar o ocorrido.

No que se refere à formação do professor, a Política Nacional de Educação Especial na Perspectiva da Educação Inclusiva enfatiza:

[...] como base da sua formação, inicial e continuada, conhecimentos gerais para o exercício da docência e conhecimentos específicos da área. Essa formação possibilita a sua atuação no atendimento educacional especializado e deve aprofundar o caráter interativo e interdisciplinar da atuação nas salas comuns do ensino regular, nas salas de recursos, nos centros de atendimento educacional especializado. (BRASIL, 2008, p. 18).

Ademais, como previsto na LDB, 9.394/96, o professor responsável pelo AEE deve possuir especialização adequada em atendimento especializado, enquanto o professor regente de classes comuns do ensino regular deve ter capacitação permanente para a inclusão dos educandos com deficiência em suas aulas. Vale lembrar a diferença entre professores capacitados e professores especializados. Os capacitados, de acordo com Dorneles (2013), são os regentes do ensino regular, de turmas comuns em que, na sua formação, constam disciplinas da área da Educação Especial, a fim de que tenham condições de trabalhar com educandos com deficiência; e os especializados devem possuir conhecimento especializado em Educação Especial ou em uma de suas áreas, podendo ser considerados, para fins de formação, cursos complementares de estudos e/ou especialização em nível de pós-graduação. 


\section{SABERES PEDAGÓGICOS}

Revista do Curso de Graduaçào de Pedagogia - Unesc

ISSN 2526-4559

Tendo em vista as especificidades do professor do AEE, salienta-se a relevância da formação necessária e inerente ao trabalho pedagógico dos educandos, no qual se estabeleça uma continuidade nos atendimentos e nos encontros. Deve-se destacar que, para Milanese (2011), a formação do professor para atuar no AEE é bastante complexa, pois possui grande exigência de habilidades e de conhecimentos, como: a) compreender as necessidades educacionais de todos os alunos com deficiências, transtornos globais de desenvolvimento e/ou altas habilidades/superdotação; b) estar disposto a trabalhar com todos os níveis e modalidades de ensino (educação infantil, ensino fundamental, ensino médio, ensino superior, educação do campo, educação tecnológica, educação de jovens e adultos) e em todos os locais de atendimento (escolas especiais, classes de recursos, classes hospitalares, ensino domiciliar). Por essas razões, é importante discutir sobre as práticas pedagógicas no AEE, tema que foi aprofundado na pesquisa de campo que aqui se apresenta.

\section{METODOLOGIA, APRESENTAÇÃO E ANÁLISE DE DADOS}

A presente pesquisa buscou analisar como é desenvolvida a prática pedagógica de uma professora da sala de recursos multifuncionais integrante do AEE em uma Escola do Município de Passo de Torres/SC, discutindo sua articulação com o ensino regular. Nesse sentido, essa pesquisa é de natureza básica, de cunho qualitativo e descritivo, pois, de acordo com Pinheiro (2010), a pesquisa básica tem como objetivo "gerar conhecimentos para o avanço da ciência sem aplicação prática prevista.” (PINHEIRO, 2010, p.19). Já, a pesquisa qualitativa, é caracterizada pela gama de detalhes dos significados e demonstrada pelos pesquisados, cujo processo se constitui no foco essencial dessa abordagem. Sendo do tipo descritiva, "visa descrever as características de determinada população ou fenômeno de relações entre variáveis." (PINHEIRO, 2010, p. 22).

Do mesmo modo, caracteriza-se como um estudo de caso, pois foi realizada por meio de aprofundamento e estudo de um caso específico, a partir do qual se buscou um amplo e detalhado conhecimento. O sujeito pesquisado foi a professora responsável pela Sala de Recursos Multifuncionais de aprendizagem, que integra o serviço do AEE. 
Vale ressaltar que, antes de se iniciar a pesquisa, foi entregue à Escola o Termo de Consentimento para autorização da investigação, que obteve positiva aceitação do Diretor Geral. Também foi entregue à professora o Termo de Consentimento de Participação na Pesquisa, o qual dá amparo legal ao não-uso de sua imagem e identificação, além do comprometimento com o sigilo dos dados coletados. Assim sendo, para atender as finalidades deste trabalho de investigação, foi realizada uma entrevista narrativa, que:

[...] se caracteriza como ferramenta não estruturada, visando a profundidade, de aspectos específicos, a partir das quais emergem histórias de vida, tanto do entrevistado como as entrecruzadas no contexto situacional. Esse tipo de entrevista visa encorajar e estimular o sujeito entrevistado (informante) a contar algo sobre algum acontecimento importante de sua vida e do contexto social. (MUYLAERT et al, 2014, p. 194).

A entrevista com a professora ocorreu no horário de intervalo entre um atendimento e outro, na Sala de Recursos Multifuncionais. Durante a entrevista, a professora sugeriu não gravar as falas. Todavia, a pesquisadora procurou descrever com atenção todo o discurso, sendo fiel às respostas e às narrativas da entrevistada.

Além da entrevista com a professora, pretendia-se também consultar o Projeto Político Pedagógico da escola para identificar a concepção de inclusão proposta pelo coletivo da comunidade escolar. Contudo, não foi possível realizar essa análise, pois a estagiária foi informada pelo diretor que o Projeto estava passando por processo de avaliação.

Ademais, foram analisados os Planos de aula da professora, com base nos quais foram identificados os objetivos e as atividades propostas às necessidades específicas de cada educando. A professora revelou que se preocupa com a aprendizagem do aluno, pois, para cada um, existe um Plano de aula diferenciado, os quais prospectam atendimentos individualizados. Entretanto, ainda que a professora atenda educandos com a mesma deficiência, ela elabora planos diferentes, cada um com sua singularidade, demonstrando o seu entendimento de que, mesmo que um indivíduo possua deficiência igual, há características próprias envolvidas.

Nesse sentido, a professora realiza diagnósticos escritos dos educandos: primeiramente, faz a descrição dos laudos médicos, analisa documentos e observações vindas de outros educadores (caso o aluno venha de outras instituições), realiza os primeiros registros 


\section{SABERES PEDAGÓGICOS}

Revista do Curso de Graduaçào de Pedagogia - Unesc

ISSN 2526-4559

e coloca junto à pasta do educando. Após, são iniciados os atendimentos, começando com uma análise do primeiro encontro, cujos olhares são coletados por meio de anotações da professora.

Os Planos de Ensino apresentam tema, objetivos, conteúdos e procedimentos metodológicos, que, segundo a professora, são baseados por uma indagação dos educandos, podendo ser sobre alguma mudança climática, alguma comemoração do mês, etc. Sempre há alternância das atividades, entre teoria e prática, que se apresentam de maneiras diversas e diferenciadas. A professora afirma também que acontece de estar com um Plano de aula que possua mais atividades escritas e, quando o atendimento inicia, percebe que o educando está disperso e não consegue se concentrar, então modifica a atividade, deixando-a mais flexível e apresentando mais atividades práticas.

Acerca dos dados coletados na entrevista, verificou-se que a professora é graduada em Pedagogia e Fonoaudiologia, tem Especialização em Educação Especial, Psicopedagogia e Mestrado em Educação. Além disso, participou de cursos complementares em Libras e AEE, e também atua no ensino superior.

Hoje, realiza capacitações sobre "Ética do professor" pela empresa Microlins e em outros espaços para onde é convidada. Com frequência, participa de cursos, de simpósios e de palestras sobre a educação especial; frisou, em vários momentos da entrevista, a importância da formação continuada para os professores, no sentido de adquirir mais experiência. Vale destacar que é graduada há quarenta anos e aposentada pela Unisys Brasil Ltda, empresa multifuncional no ramo de tecnologias e de informática, na qual realizava um trabalho de aporte pedagógico a todos os funcionários, tendo objetivo de gerar mudanças de comportamento, tanto na sua atuação profissional, quanto na atuação pessoal, familiar e interpessoal.

Sobre sua atuação no AEE, a entrevistada disse que passava férias na cidade de Passo de Torres/SC, quando surgiu um concurso público que lhe chamou atenção; inscreveu-se na área pretendida e ficou em primeiro lugar, assumindo a função no ano de 2017. Com a sua admissão, foi implantada no Município a Sala de Recursos Multifuncionais na Escola ${ }^{6}$, sendo ela a primeira professora.

\footnotetext{
${ }^{6}$ Sobre os motivos da implantação da Sala de Recursos Multifuncionais na referida escola, a professora relatou a procura de pais para vagas no AEE, para que houvesse suplementação e/ou complementação pedagógica necessária aos seus filhos, pois eles apresentam deficiências.
}

Saberes Pedagógicos, Criciúma, v. 5, nº1, janeiro/abril 2021. - Curso de Pedagogia - UNESC 


\section{SABERES PEDAGÓGICOS}

Revista do Curso de Graduaçào de Pedagogia - Unesc

ISSN 2526-4559

A professora foi questionada sobre o público-alvo e quais as suas necessidades pedagógicas, cuja resposta esclareceu os serviços prestados se dão para educandos que possuem alguma deficiência e que dispõem de laudos médicos; ressaltou que os pais devem assinar um termo de compromisso e se responsabilizar por levar e buscar o educando. No caso da sua sala, atende atualmente vinte e um alunos, com as seguintes deficiências, transtornos ou distúrbios: transtorno de déficit de atenção e hiperatividade, autistas, perda auditiva, síndrome de down e distúrbio da fala.

Outra questão apresentada foi sobre o papel do professor no processo de ensinoaprendizagem dos educandos, sendo que a resposta apresentada esclarece que o professor deve se despir de todo e qualquer preconceito e estar na sua íntegra, dando o seu melhor. Destacou que, dentro da escola, o educando pode ver o professor do AEE como seu primeiro acesso, seu porta-voz, por isso a importância de se "entregar nos atendimentos".

Afirma Dorneles (2013, p. 83) que "as práticas das professoras de Educação Especial hoje nas escolas estão permeadas por diversas atividades que são necessárias para a inclusão e permanência dos alunos e para melhorar sua qualidade de vida." Percebe-se, então, a concordância da professora com as ideias de Dorneles (2013), uma vez que busca acolher o aluno em suas necessidades.

Milanesi (2011) diz que a função do professor é estar e se fazer disponível para o educando quando ele necessitar; articular o exercício de sua docência e de seus conhecimentos específicos da área com os conhecimentos dos alunos; trazê-los para experiências significativas e, ainda, demonstrar que as práticas pedagógicas serão diferenciadas a cada atendimento. Essa ideia vem ao encontro da fala da professora quando diz que todas as atividades que ocorrem nos atendimentos servem para a verdadeira inclusão dentro da escola e fora dela, valendo lembrar que as práticas pedagógicas promovem, além da inclusão, a permanência dos alunos no ambiente escolar.

Dorneles (2013) diz também que existe evasão de educandos com deficiência, transtornos globais de desenvolvimento e/ou altas habilidades/superdotação, reforçando a fala da professora sobre o valor das atividades que acolham os alunos, para haver um bom desenvolvimento social no que lhe diz respeito.

Saberes Pedagógicos, Criciúma, v. 5, nº1, janeiro/abril 2021. - Curso de Pedagogia - UNESC 
Quando indagada sobre os tipos de atendimento realizados, a professora salienta a relevância do diagnóstico e da necessidade demonstrada pelos educandos a cada atendimento. Ressaltou que alguns estudantes autistas precisam de uma fala com tom mais baixo e mais devagar. Cita, também, que um educando com síndrome de down gosta mais de barulho, de atividades coloridas, materiais grandes, fáceis de manusear.

Conforme traz a Cartilha do AEE (BRASIL, 2007, p. 22), deve-se privilegiar o desenvolvimento e a superação das maiores dificuldades dos educandos com deficiência, como "para o cego, a possibilidade de ler pelo braile; para o surdo, a forma mais conveniente de se comunicar e para a pessoa com deficiência física, o modo mais adequado de se orientar e se locomover." Então, percebe-se a necessidade específica que cada educando traz consigo.

Nessa mesma pergunta, discutiu-se sobre as atividades realizadas nos atendimentos, para o quê a professora ressaltou que, para o educando com dificuldade na fala, por exemplo, criou, com um tubo de PVC, um "sussurrofone", o qual faz o maior sucesso e possui uma aceitação interessante, pois faz com que os educandos se desenvolvam por meio de um atendimento lúdico. Nesse sentido, os atendimentos com o "sussurrofone" ocorrem da seguinte forma: o educando chega para o atendimento e é apresentado a ele um tubo de PVC construído artesanalmente pela professora, que funciona como um telefone, no qual o aluno fala e ouve sua voz através dele; serve para estimular a fala, estimular a leitura e melhorar a pronúncia das palavras.

Para outros atendimentos, a professora utiliza muito da "imagética" (exploração do visual e do gestual), de sons (com diferenciadas músicas e instrumentos musicais), da contação de histórias (desde o uso de livros comuns com diversos personagens, até livros de tecidos, com alto relevo, com muito colorido). Cita, também, o uso de fantoches, de ursos, de bonecos, enfim, de uma gama de materiais e brinquedos que auxiliam para que sejam desenvolvidas todas as características dos alunos.

Vale lembrar que muitos materiais, segundo a professora, são construídos no decorrer dos encontros, como montar personagens de uma história com o uso de palitos, de tecidos, de cola, criar jogos matemáticos com uso de papelão, de recortes de revistas, elaborar tabelas sobre sequência de letras, com formas geométricas, ou seja, uma gama de atividades, 
que auxiliam cada educando a perceber sua contribuição no material desenvolvido. Após a construção, são utilizados nos seus atendimentos diários.

Essa prática da professora vem ao encontro do que orienta a Política Nacional de Educação Especial na Perspectiva da Educação Inclusiva (2008) sobre atividades desenvolvidas no atendimento educacional especializado, as quais devem se diferenciar daquelas realizadas no ensino regular. Nota-se a importância das duas modalidades de ensino no trabalho com os alunos, a saber: a) ensino regular: com trabalhos em grupo e pesquisas coletivas; e b) AEE: um ensino individual, com um plano que atende necessidades e especificidades.

Discutiu-se, também, sobre a forma de avaliar a aprendizagem e os critérios avaliativos. A respeito disso, a professora disse que ocorre uma avaliação contínua, utilizandose dos registros dos educandos arquivados em pasta, desde o primeiro atendimento. Com o passar dos atendimentos, são feitos diagnósticos e constatações da evolução ou não dos alunos. A professora frisa que sempre nota alguma mudança, seja no comportamento, na aprendizagem ou nas relações interpessoais com os outros colegas. Salientou que frequenta, algumas vezes, a sala do ensino regular do educando e o observa, verificando como está seu desenvolvimento e a inclusão no ambiente escolar.

Sobre a avaliação da aprendizagem, a Cartilha do AEE aponta que:

[...]faz parte do processo de ensino e de aprendizagem, de forma contínua. Procura-se conhecer não apenas os progressos, mas também as estratégias de trabalho utilizadas pelos alunos. Utilizam-se diferentes instrumentos de avaliação, como relatórios semestrais com observações individuais e coletivas, além dos portfólios onde estão contidas todas as observações e construções dos alunos durante a execução das atividades. (BRASIL, 2007, p. 31).

Como visto, as falas da professora se aproximam das orientações proposta na Cartilha do AEE (BRASIL, 2007) no que diz respeito à avaliação continuada, por meio de processos e de constantes observações; também verbalizou sobre diagnósticos, podendo ser comparados aos "relatórios semestrais", pois traduzem a ideia de um conjunto de informações do educando, acordando consideravelmente a importância de não deixar passar em branco observações e registros. A Cartilha do AEE (BRASIL, 2007), revela que o uso do portfólio se faz necessário para o conhecimento do aluno, identificando-o como um ótimo instrumento de

Saberes Pedagógicos, Criciúma, v. 5, nº1, janeiro/abril 2021. - Curso de Pedagogia - UNESC 
avaliação. Nesse sentido, assemelha-se na fala da professora, a pasta (local de seus arquivos e apontamentos), com o termo portfólio, utilizado na Cartilha do AEE (BRASIL, 2007).

A docente relatou também que observa em todos os atendimentos a evolução do educando, percebendo em quais atividades possui mais facilidade e em qual tem mais dificuldade. Nesse sentido, propõe atividades conjuntas com as do ensino regular, para demonstrar aos outros educandos que seu colega "diferente" ${ }^{7}$ consegue realizar determinadas atividades com muita aptidão.

As DCNs (BRASIL, 2013, p. 284) registram que "estabelecer articulação com os professores da sala de aula comum, visando à disponibilização dos serviços, dos recursos pedagógicos e de acessibilidade e das estratégias que promovem a participação dos alunos nas atividades escolares." Similarmente ao depoimento da professora, os educandos do ensino regular passam então a compreender um pouco as possibilidades do colega com deficiência.

No atendimento individual, a professora conta que alguns educandos com autismo possuem facilidade com movimentos de pinça, que fazem bolinhas bem pequenas, que elaboram outras maiores, todas bem redondas, tendo como matéria-prima a massa de modelar. Ela ainda percebe que esses alunos classificam as bolinhas por cores e por tamanho, constatando que os educandos possuem uma organização mental, dispondo uma sequência lógica e apontando a atividade produzida por eles.

Para demonstrar essa habilidade do educando com deficiência na sala do ensino regular, a professora pesquisada leva massa de modelar para todos os colegas trabalharem juntos, então o amigo intitulado "diferente" se sai muito bem, e todos os outros passam a perceber que cada um possui habilidades com determinadas atividades e dispõe de singularidades, o que os fazem serem únicos no mundo. Como se nota, a prática da professora contribui para promover a inclusão dos alunos com deficiência na escola, incentivando sua comunicação com os demais e o desenvolvimento de suas potencialidades.

Sobre isso, Fiegenbaun (2009, p. 20) diz que

Devem existir práticas pedagógicas adequadas e inovadoras, que deixem de ocasionar as dificuldades escolares e consequentemente a exclusão dos alunos. Práticas que

\footnotetext{
${ }^{7}$ Com deficiência, distúrbios e/ou transtornos.

Saberes Pedagógicos, Criciúma, v. 5, nº 1, janeiro/abril 2021. - Curso de Pedagogia - UNESC
} 
permitam desenvolver mecanismos e novas estratégias para possibilitar a aprendizagem de todos.

A autora coloca também acerca das "situações de desvantagem" de alunos com deficiência, como se eles não soubessem ou não entendessem qualquer atividade proposta em aula. Nesse ponto, relacionando a atividade citada pela professora, todos os envolvidos conseguem perceber a evolução do aluno "diferente". Além disso, pode-se averiguar que todos os educandos com deficiência que frequentam o ensino regular possuem diferentes maneiras de se expressar nas atividades recomendadas tanto pelo professor do AEE como pelo regente do ensino regular.

Nesse aspecto, questionada sobre o trabalho do segundo professor, a entrevistada disse que deve ser visto como um professor da turma e não somente do educando com deficiência, pois, quando visto apenas como exclusivo daquele aluno, existe uma exclusão precoce do educando ao relacionar-se com os outros colegas de classe. Ainda, de acordo com a professora, os segundos professores daquela escola são graduandos de licenciaturas, em Pedagogia, Educação Física e Artes Visuais, contratados para estágios pela Prefeitura, junto ao Centro de Integração Empresa-Escola - CIEE.

A professora citou também que educandos diagnosticados em um grau severo de deficiência são diretamente encaminhados à Associação de Pais e Amigos dos Excepcionais (APAE). Destaca-se, ainda, que alguns frequentam o ensino regular e o AEE, mas também recebem acompanhamento pedagógico na APAE.

\section{CONCLUSÃo}

A realização desta pesquisa possibilitou compreender o desenvolvimento da prática pedagógica de uma professora do AEE em uma Escola do Município de Passo de Torres/SC por meio de entrevista narrativa. Observou-se que, nessa escola, o público atendido se constitui de vinte e um alunos no seu total, com deficiências, transtornos ou distúrbios. Para atender esse público, a professora pesquisada se dedica de forma intensiva aos atendimentos, promovendo contato entre a escola, o professor do ensino regular e a família do aluno. 


\section{SABERES PEDAGÓGICOS}

Revista do Curso de Graduaçào de Pedagogia - Unesc

ISSN 2526-4559

A professora elabora Planos de Ensino específicos para cada aluno, para que possa contemplar as suas características de aprendizagem. Nesse sentido, as atividades propostas são diferenciadas, diversificadas, significativas, teóricas e práticas, buscando sempre estimular o interesse dos alunos. A articulação com o ensino regular ocorre por meio de encontros entre ela e professores desse ensino, para que discutam sobre o desenvolvimento e a aprendizagem dos educandos, bem como a avaliação, buscando rever suas estratégias para melhor atender a esses sujeitos.

Em virtude dos aspectos coletados e analisados nesta pesquisa, levando em conta a prática pedagógica da professora com os atendimentos especializados para com seus alunos do AEE, nota-se uma dedicação continuada de sua parte, sempre procurando promover melhores encontros, desenvolvendo atividades diferenciadas, estabelecendo relação entre teoria e prática, superando todas as adversidades encontradas. Finalizamos este trabalho com a certeza de que, de fato, não se finda aqui, mas, assim como a professora, que estejamos sempre motivados a nos especializar e a proporcionar aos nossos alunos diversas situação de aprendizagem.

\section{REFERÊNCIAS}

BRASIL. Constituição. Constituição da República Federativa do Brasil. Brasília, DF: Senado Federal: Centro Gráfico, 1988. Disponível em: https://www2.camara.leg.br/legin/fed/consti/1988/constituicao-1988-5-outubro-1988-322142publicacaooriginal-1-pl.html. Acesso em: 09 mai.2018.

BRASIL. Ministério da Educação. Lei de Diretrizes e Bases da Educação. 1996. Disponível em: http://www.planalto.gov.br/Ccivil_03/leis/L9394.htm. Acesso em: 09 mai.2018.

BRASIL. Ministério da Educação. Cartilha do AEE: formação continuada a distância de professores para o atendimento educacional especializado. - Brasília: SEESP, SEED, 2007. Disponível em: http://portal.mec.gov.br/seesp/arquivos/pdf/aee_ead.pdf. Acesso em: 09 mai.2018.

BRASIL. Ministério da Educação. Política Nacional de Educação Especial na Perspectiva da Educação Inclusiva. 2008. - Brasília: SEACADI. 19p. Disponível em: http://portal.mec.gov.br/arquivos/pdf/politicaeducespecial.pdf. Acesso em: 09 mai.2018. 


\section{SABERES PEDAGÓGICOS \\ Revista do Curso de Graduaçào de Pedagogia - Unesc \\ ISSN 2526-4559}

BRASIL. Ministério da Educação. Resolução no 4 de 2009. Diário Oficial da União. Brasília: CNE, CEB, 2009. Disponível em: http://portal.mec.gov.br/dmdocuments/rceb004_09.pdf. Acesso em: 03 abr.2018.

BRASIL. Ministério da Educação. Manual de orientação: Programa de Implantação de Sala de Recursos Multifuncionais. Brasília: SEE. 2010. Disponível em: http://portal.mec.gov.br/index.php?option=com_docman\&view=download\&alias=9936manual-orientacao-programa-implantacao-salas-recursos-multifuncionais\&Itemid=30192. Acesso em: 11 mar.2018.

BRASIL. Ministério da Educação. Resolução no 436 de 2012. Brasília. 2012. Disponível em: Acesso em: http://www.normasbrasil.com.br/norma/resolucao-436-2012-ce_239085.html. 09 mai.2018.

BRASIL. Ministério da Educação. Diretrizes Curriculares Nacionais Gerais da Educação Básica. Secretária de Educação Básica. Diretoria de Currículos e Educação Integral. Brasília: SEB, DICEI, 2013. 542p. Disponível em: Acesso em: 09 mai.2018.

BRASIL. Estatuto da pessoa com deficiência. Lei $\mathbf{n}^{\mathbf{0}}$ 13.146. Lei Brasileira de Inclusão. Brasília. 2015. Disponível em: http://www.punf.uff.br/inclusao/images/leis/lei_13146.pdf. Acesso em: 23 mar.2019.

BRASIL. Conselho Estadual de Educação de Santa Catarina. Resolução no 100, de 13 de dezembro de 2016. Disponível em: http://www.cee.sc.gov.br/index.php/legislacaodownloads/educacao-basica/outras-modalidades-de-ensino/educacao-basica/educacao-basicaensino-especial-resolucoes/1359-resolucao-2016-100-cee-sc. Acesso em: 25 mar.2019.

BRASIL. Ministério da Educação. Documento orientador programa implantação de salas de recursos multifuncionais. Brasília: SECADI, DPEE, CGPAE. Disponível em: http://portal.mec.gov.br/index.php?option=com_docman\&view=download\&alias=9936manual-orientacao-programa-implantacao-salas-recursos-multifuncionais\&Itemid=30192. Acesso em: 04 abr.2019.

DORNELES, Marciele Vieira. Em cena: a constituição do professor do atendimento educacional especializado. UFSM. Santa Maria, 2013. 103 p. Disponível em: https://repositorio.ufsm.br/bitstream/handle/1/7102/DORNELES\%2C\%20MARCIELE\%20VI EIRA.pdf?sequence=1\&isAllowed=y. Acesso em: 09 mai.2018.

FIEGENBAUM. Josiane. Acessibilidade no contexto escolar: tornando a inclusão possível. UFRGS. Porto Alegre, 2009. 32 p. Disponível em: https://www.lume.ufrgs.br/bitstream/handle/10183/33297/000726075.pdf. Acesso em: 03 mar.2018.

MILANESI. Josiane Beltrame. Formação de professores e a legislação atual para o atendimento educacional especializado. UFSCAR. 2011. 10 p.

Saberes Pedagógicos, Criciúma, v. 5, nº1, janeiro/abril 2021. - Curso de Pedagogia - UNESC 
MUYLAERT. Camila Junqueira. Entrevistas narrativas: um importante recurso em pesquisa qualitativa. São Paulo, 2014. Disponível em:

http://www.scielo.br/pdf/reeusp/v48nspe2/pt_0080-6234-reeusp-48-nspe2-00184.pdf. Acesso em: 09 mai.2018.

PINHEIRO. José Maurício dos Santos. Da iniciação científica ao TCC uma abordagem para os cursos de tecnologias. USP. Rio de Janeiro. 2010. 